\title{
Síndrome pulmonar e cardiovascular por hantavírus*
}

\author{
H antavirus pulmonary and cardiovascular syndrome
}

\author{
Mariangela Pimentel Pincelli (te sbpt), Carmen Sílvia Valente Barbas² (te sbpt), \\ Carlos Roberto Ribeiro de Carvalho ${ }^{3}$ (Te SBPt), Luiza Terezinha Madia de Souza ${ }^{4}$, \\ LUÍS TADEU MORAES FIGUEIREDO ${ }^{5}$
}

A síndrome pulmonar e cardiovascular por hantavírus é uma doença de conhecimento relativamente recente e freqüentemente fatal, apresentando-se como síndrome do desconforto respiratório agudo. No Brasil, desde o primeiro surto, relatado em novembro/ dezembro de 1993, em Juquitiba, 226 casos já foram registrados pela Fundação Nacional da Saúde. A doença afeta indivíduos previamente hígidos, apresentando-se com pródromo febril e sintomas semelhantes aos de um resfriado comum, podendo rapidamente evoluir para edema pulmonar, insuficiência respiratória aguda e choque. A hemoconcentração e a plaquetopenia são comuns da síndrome pulmonar e cardiovascular por hantavírus, e o quadro radiológico típico é de um infiltrado intersticial bilateral difuso, que progride rapidamente para consolidações alveolares, paralelamente à piora do quadro clínico. A mortalidade inicial era em torno de $75 \%$ e declinou para aproximadamente $35 \%$, nos últimos anos. Os pacientes que sobrevivem geralmente recuperam-se completamente, cerca de uma semana após o estabelecimento do quadro respiratório. 0 agente causal, não reconhecido até há pouco, foi identificado como um hantavírus, cujo reservatório natural são animais roedores da família Muridae, subfamília Sigmodontinae. 0 tratamento específico antiviral ainda não é bem estabelecido, estando em estudo a eficácia de ribavirina. Cuidados de terapia intensiva como ventilação mecânica e monitoramento hemodinâmico invasivo são necessários nas formas mais graves da doença. Essas medidas, se instituídas precocemente, podem melhorar o prognóstico e a sobrevida dos pacientes com síndrome pulmonar e cardiovascular por hantavírus. (J

Pneumol 2003;29(5):309-24)

Descritores - Síndrome pulmonar por hantavírus/ diagnóstico. Infecções por hantavirus/ diagnóstico. Brasil.

* Trabalho realizado na Disciplina de Pneumologia - Faculdade de M edicina da U niversidade de São Paulo, São Paulo, SP.

1. Mestre e Doutoranda em Pneumologia. Médica Pneumologista e Intensivista. Título de especialista pela Sociedade B rasileira de Pneumologia e Tisiologia.

2. Livre-Docente da Disciplina de Pneumologia. Assistente da UTI Respiratória. Título de especialista pela Sociedade Brasileira de Pneumologia e Tisiologia.

3. Livre-Docente da Disciplina de Pneumologia. Chefe da UTI Respiratória. Título de especialista pela Sociedade Brasileira de Pneumologia e Tisiologia.
Hantavirus pulmonary and cardiovascular syndrome is a recently identified and often fatal disease, which presents as acute respiratory distress syndrome (ARDS). Since the first outbreak, in Nov/ Dec 1993, in J uquitiba, Brazil, 226 cases have been registered by FUNASA (National $\mathrm{H}$ ealth Foundation). ${ }^{(4)}$ The disease occurs in previously healthy subjects, presenting with fever and symptoms similar to the common cold, and may rapidly evolve to pulmonary edema, respiratory failure and shock. Hemoconcentration and thrombocytopenia are common features, and the typical radiological finding is a bilateral diffuse interstitial infiltrate that evolves to alveolar consolidations in parallel to the worsening of the clinical condition. Initially, mortality was around $75 \%$, but it declined to approximately $35 \%$ in the last few years. Patients who survive usually recover completely, about a week after the onset of the respiratory symptoms. The causal agent is a previously unrecognized hantavirus whose natural reservoirs are rodents of the family Muridae, sub-family Sigmodontinae. Specific antiviral treatment for hantavirus pulmonary and cardiovascular syndrome has not yet been well established, and the efficacy of ribavirin is currently being studied. Intensive care, including mechanical ventilation and invasive hemodynamic monitoring, is required for the more severe presentations of the disease. These measures may improve the prognosis and survival of patients with hantavirus pulmonary and cardiovascular syndrome if started early in the course of the disease.

Key words - Hantavirus pulmonary syndrome/ diagnoses. Hantavirus infections/ diagnoses. B razil.

4. Diretora do Serviço de Virologia do Instituto A dolfo Lutz.

5. Livre-Docente. Responsável pela Unidade Multidepartamental de Pesquisa em Virologia.

Endereço para correspondência - Rua Dona Maria J acinta, 241, 10을 andar, sala 102 - 13561-120 - São Carlos, SP. Tel.: (16) 270-1667; e-mail: mariangelapincelli@itelefonica.com.br

Recebido para publicação em 25/4/03. Aprovado, após revisão, em 11/6/03. 


\section{INTRODUÇÃO}

A síndrome pulmonar e cardiovascular por hantavírus foi reconhecida pela primeira vez em 1993, na região semi-árida do Sudoeste dos EUA, onde se avizinham os Estados de Arizona, Novo México, Colorado e Utah.(1-3) A mortalidade nesse surto inicial foi de aproximadamente $80 \%$. ${ }^{(2)} \mathrm{Na}$ ocasião, após numerosos testes diagnósticos, observou-se que o soro dos pacientes reagia contra hantavírus já conhecidos, por causarem febre hemorrágica com síndrome renal (FHSR) na Eurásia. ${ }^{(1-3)}$ A fraca reatividade sorológica sugeria tratar-se de um hantavírus ainda não reconhecido até então. Cerca de oito semanas após o comunicado dos primeiros casos, conseguiu-se determinar que a doença era causada por um outro hantavírus, ${ }^{(4)}$ causador de doença humana com quadro clínico muito distinto da FHSR e que foi chamada inicialmente de síndrome de hantavirose pulmonar ${ }^{(2,3,5-7)} \mathrm{e}$, posteriormente, após a determinação da existência de colapso cardiocirculatório associado à alta letalidade da síndrome, convencionou-se chamá-la de síndrome pulmonar e cardiovascular por hantavírus (SPCVH). ${ }^{(3,8)}$

$O$ vírus causador, analisado a partir de amplificação gênica de partículas virais de materiais de necropsia, foi denominado inicialmente Four Corners, Muerto Canyon ou Little Water, em alusão às localidades de onde se originaram os casos. ${ }^{(4-7)}$ Entretanto, após reclamação da população local, preocupada com a reputação das localidades ao serem relacionadas a vírus tão letal, optou-se por denominá-lo Sin Nombre, como uma forma de trocadilho. ${ }^{(7,9,10)}$

Também em 1993, conseguiu-se determinar o animal reservatório do vírus Sin Nombre: um roedor conhecido como rato veadeiro (deer mouse - Peromyscus maniculatus), capturado nas proximidades das moradias dos doen-

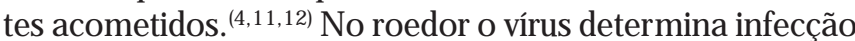
crônica, aparentemente sem causar doença. As partículas virais são eliminadas através da saliva, fezes e, especialmente, urina do animal. ${ }^{(12)}$

\section{Hantavírus e roedores-reservatório}

H antavírus são RNA vírus esféricos, envelopados, medindo cerca de 80 a $120 \mathrm{~nm}$. O RNA viral é de fita simples, trissegmentado e com polaridade negativa. Os segmentos de RNA são denominados: L (large - grande) que codifica a transcriptase viral, $M$ (medium - médio) que codifica as glicoproteínas da cápside e S (small - pequeno) responsável pela codificação da proteína da nucleocápside viral. ${ }^{(2-4,7)}$

$\mathrm{O}$ nome hantavírus refere-se ao $\mathrm{H}$ antaan, primeiro vírus do gênero, descrito em 1976 e que foi isolado de um roedor na Coréia, nas proximidades do rio com esse mesmo nome. ${ }^{(13)}$ Esse vírus causou cerca de 3.700 casos de
Siglas e abreviaturas utilizadas neste trabalho

ALT - A lanina transaminase

DHL - Desidrogenase láctica

FHSR - Febre hemorrágica com síndrome renal

Funasa - Fundação Nacional de Saúde

PAF - Fator de ativação plaquetária

RT-PCR - Reação de polimerização em cadeia para a transcrip-

tase reversa

SDRA - Síndrome de desconforto respiratório agudo

SPCVH - Síndrome pulmonar e cardiovascular por hantavírus

TNF - Fator de necrose tumoral

FHSR, doença anteriormente conhecida como febre hemorrágica da Coréia e que acometeu a tropa dos Estados Unidos, que ali lutou na década de 50.(14,15)

A tualmente, a FHSR tem incidência de 100 a 200 mil casos anuais, particularmente na China. $\mathrm{Na}$ Ásia, os hantavírus encontram-se vinculados principalmente aos roedores da subfamília Muridae e na Europa, aos da subfamília Arvicolinae. ${ }^{(14-16)}$

Dentre os hantavírus da Eurásia, o hospedeiro primário do vírus Hantaan é o rato do campo - Apodemus agrarius. 0 vírus Dobrava, também causador de FHSR grave na Á sia e na Europa do Leste, associa-se ao roedor A podemus flavicollis e o vírus Seoul determina uma forma menos grave de doença, com fatalidade menor que $1 \%$, a qual tem sido identificada principalmente na Ásia, tendo como hospedeiro primário o Rattus norvegicus. Também o vírus Puumala é responsável por uma forma leve de FHSR, especialmente na Escandinávia e Europa O riental e possui como hospedeiro primário o roedor Clethrionomys glareolus. ${ }^{(14-16)}$

Nas A méricas, após 10 anos de estudos sobre a SPCVH, são conhecidos vários hantavírus. Na América do Norte o vírus Sin Nombre parece ser o causador da maioria dos casos de SPCVH, (14-18) enquanto que na América do Sul o vírus Andes está implicado na determinação da maioria dos casos, no Chile e na Argentina. (20-23) Diferenças filogenéticas entre as espécies de hantavírus associam-se, diretamente, à distância geográfica entre os locais onde os vírus foram detectados. ${ }^{(19-21,24,25)}$

Os hantavírus causadores de SPCVH encontram-se associados a roedores silvestres americanos da família Muridae, subfamília Sigmodontinae. Esta subfamília contém cerca de 430 espécies. Compreende roedores selvagens diferentes daqueles conhecidos no ambiente urbano, originários do Velho Mundo, como o rato doméstico, o rato negro e o rato norueguês (estes últimos da subfamília Murinae). No entanto, algumas espécies selvagens da subfamília Sigmodontinae podem infestar habitações rurais e áreas suburbanas. (26-28) Um terceiro grupo de roedores, da subfamília Arvicolinae, relaciona-se a outros hantavírus, os quais não causam SPCVH. ${ }^{(12,18,29,30)}$ 
O principal hospedeiro do vírus Sin Nombre é o rato veadeiro (Peromyscus maniculatus), roedor disseminado nas áreas rurais da maior parte do território norteamericano, especialmente a oeste do Rio Mississipi. ${ }^{(12,18,}$ ${ }^{19,30)}$ A lém do Sin Nombre, outros hantavírus causadores da SPCVH na América do Norte são o vírus New York, associado ao rato de pata branca (Peromyscus leucopus), o vírus Black Creek Canal, cujo hospedeiro é o ratinho do algodão (Sigmodon hispidus) e o vírus Bayou, que infecta o rato do arroz (Oryzomys palustris). 0 vírus Prospect Hill, também encontrado nos EUA, não se associa a doenças humanas. $14,15,17,18)$

Numerosas espécies de hantavírus têm associação com a SPCVH na América do Sul: J uquitiba, Castelo dos Sonhos e Araraquara (Brasil); (25) Laguna Negra (Bolívia e Paraguai); Oran, Lechiguanas e Bermejo (Norte e Centro da Argentina), Andes (Chile e Argentina). ${ }^{(21-23,26,27)} \mathrm{No}$ Brasil, detectaram-se anticorpos contra hantavírus em Akodon sp (rato da mata), Oligoryzomys sp (ratinho do arroz) e Bolomys lasiurus sp (rato do rabo peludo). ${ }^{(28,31)}$

Os hantavírus parecem ter sua evolução estreitamente relacionada com o roedor reservatório e parece haver uma surpreendente co-evolução entre 0 vírus e o roedor hospedeiro através de milhares de anos. ${ }^{(24,27,28)}$ Encontram-se fragmentos genéticos do vírus incorporados no RNA mitocondrial dos roedores. ${ }^{(24)}$

Os hantavírus pertencem à família viral Bunyaviridae. Ao contrário do que ocorre com os demais gêneros dessa família, não há evidências de transmissão por vetores artrópodes no gênero Hantavirus(14,15).

\section{Transmissão}

A presença de hantavírus na saliva de roedores infectados e a importante sensibilidade destes roedores à inoculação viral por via intramuscular fazem supor que a transmissão horizontal, de roedor para roedor, deva ocorrer, possivelmente associada à competição por alimento entre os indivíduos da mesma espécie, geralmente em períodos de escassez que se seguem a períodos de grande fertilidade. ${ }^{(3,11,29,32,33)}$ Tal ocorrência dar-se-ia quando, a condições de grande e rápida reprodução de roedores, sucede-se escassez alimentar que leva à maior competição pela limitação de nutrientes. Durante o surto da região de Four Corners, $30 \%$ dos ratos capturados apresentavam-se infectados. ${ }^{(29,30)} 0$ s ratos machos adultos são os mais infectados, provavelmente por seu comportamento mais competitivo e agressivo. ${ }^{(11,27-29)}$

A transmissão de hantavírus para o homem ocorre pela inalação de partículas virais aerossolizadas, presentes nos excrementos e saliva dos roedores. ${ }^{(11,12,18,29)}$ Embora infreqüente, haveria também contágio por mordedura de animais contaminados, inoculação em pele ou mucosas apresentando solução de continuidade ou, ainda, inges-

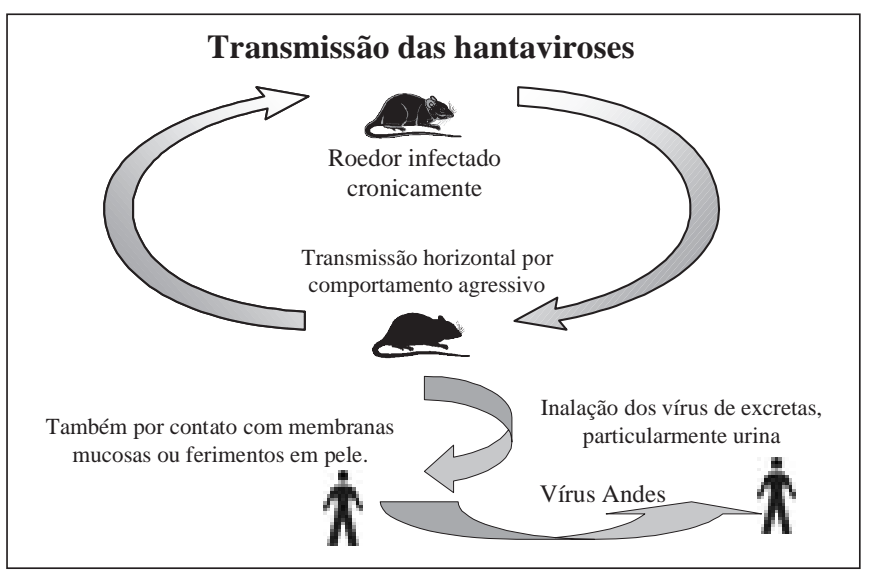

Figura 1 - Modos de transmissão das hantaviroses

tão de água ou alimentos contaminados pelo vírus(11,29) (Figura 1).

Embora nos roedores os hantavírus possam causar infecção por toda a vida, há um período de maior eliminação das partículas virais, que é de três a oito semanas pós-infecção. Outros pequenos mamíferos, predadores dos roedores, como cachorros, gatos e coiotes, também podem-se infectar, mas têm menor probabilidade de transmitir hantavírus para outros animais e seres humanos. No entanto, animais domésticos podem trazer roedores infectados capturados para o contacto com os seres humanos. $(2,3,29,30,33,34)$

Em 1996, descreveu-se um surto por vírus Andes nas proximidades de B ariloche, Argentina. A pós estudos epidemiológicos e filogenéticos, pôde-se confirmar que houve transmissão interpessoal do vírus, inclusive para cinco médicos e funcionários de serviço de saúde. Duas pessoas contaminaram-se em Buenos Aires, após transferência de pacientes da localidade inicial para hospital, nesta cidade, sem que tivessem visitado o local inicial do surto, o que despertou a suspeita, logo após confirmada, de transmissão interpessoal da SPCVH. ${ }^{(35,36)}$

\section{Epidemiologia}

Apesar de a descrição inicial da síndrome ter-se dado nos EUA, a América do Sul superou a do Norte em número de casos da SPCVH, principalmente pelas ocorrências na Argentina, Brasil e Chile(34) (OPAS, 2001 - Figura 2). Há evidências de que a infecção por vírus Andes em áreas suburbanas da Argentina e Chile possa ter estado presente e não identificada já há longo tempo. (28)

No mesmo ano em que foi descrita a SPCVH, em 1993, relatou-se o primeiro surto no Brasil, na região de J uquitiba, em área recém-desmatada da Serra do Mar, onde moravam três irmãos que contraíram a doença no intervalo de poucos dias. Este surto inicial resultou na morte de dois dos pacientes e na identificação do vírus J uquiti- 
ba. (37) Posteriormente, ainda no Estado de São Paulo, observaram-se novos casos em Araraquara e Franca e ainda em Castelo dos Sonhos, no Estado do Mato Grosso, tendo sido identificados novos vírus do gênero Hantavirus. ${ }^{(25,32-34,38)}$

Dados fornecidos pela Funasa permitem delinear o perfil epidemiológico da doença no B rasil. Nos anos iniciais, os casos relatados predominavam no Estado de São Paulo. Em 2000 e 2001, observou-se grande número de casos no Paraná(39) e em Santa Catarina e no ano de 2002 houve distribuição mais homogênea dos casos nos Estados do Sul e Sudeste do país(38) (Figura 3).

O Estado com maior número de casos é o Paraná, devido ao importante surto de 2000/2001, seguido por São Paulo, Minas Gerais, Rio Grande do Sul e Santa Catarina (Figura 4).(38,39) De outubro de 1993 a outubro de 2002 foram notificados 226 casos de SPCVH no Brasil. Observou-se número crescente de notificações da SPCVH e menor mortalidade nos anos mais recentes (Figura 5). A casuística brasileira mostra mortalidade média de cerca de $34 \%$. Não há predomínio quanto ao sexo e à faixa etária

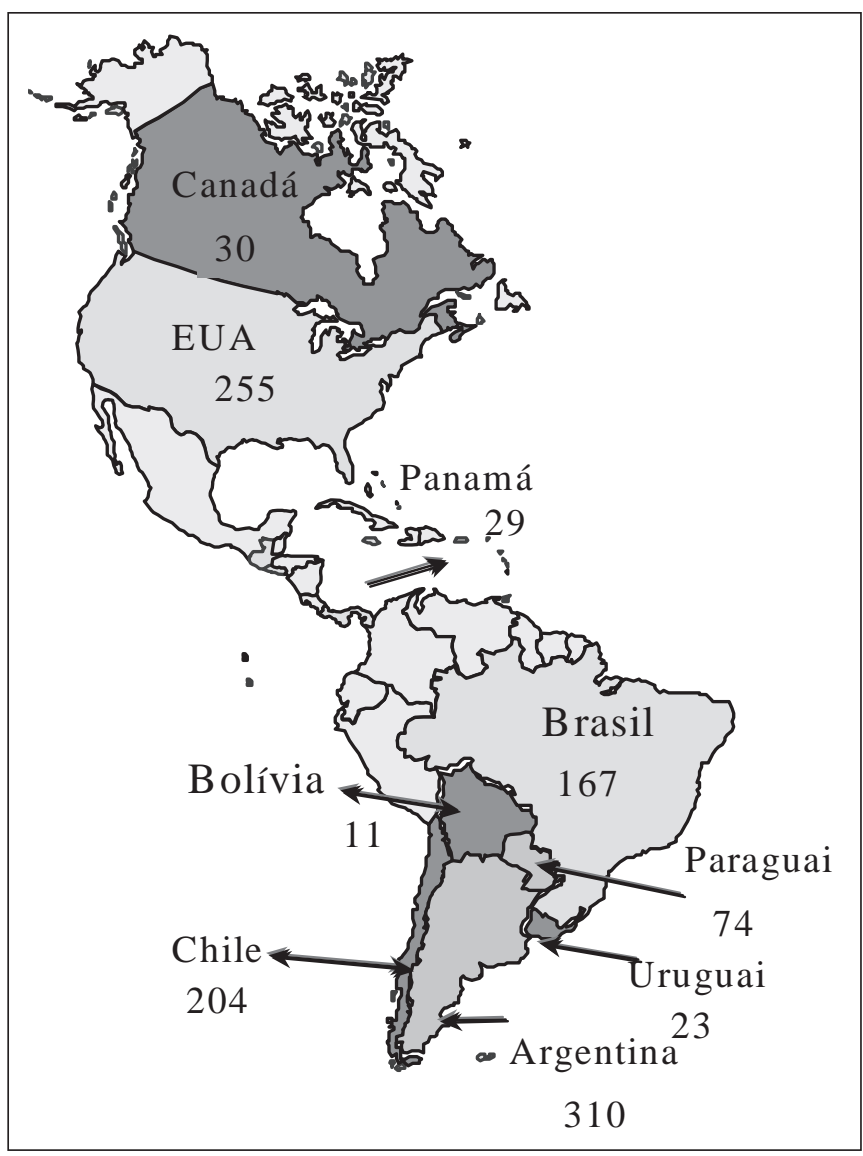

Figura 2 - Número de casos de SPCVH por países nas Américas, até 2001 (modificado da fonte: www. paho.org/English/HCP/HCT/ EER/H antavirus2002.htm) mais afetada é a de adultos jovens, refletindo, talvez, a exposição a roedores durante a atividade laboral. ${ }^{(38,39)}$

Múltiplos fatores devem ser levados em conta no estudo epidemiológico desta zoonose emergente para que se

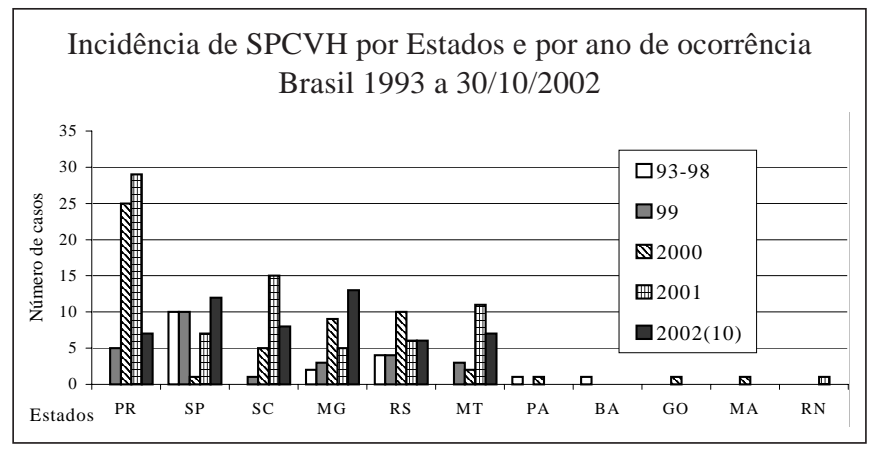

Figura 3 - Distribuição dos casos de SPCVH no Brasil, segundo ano e local de ocorrência

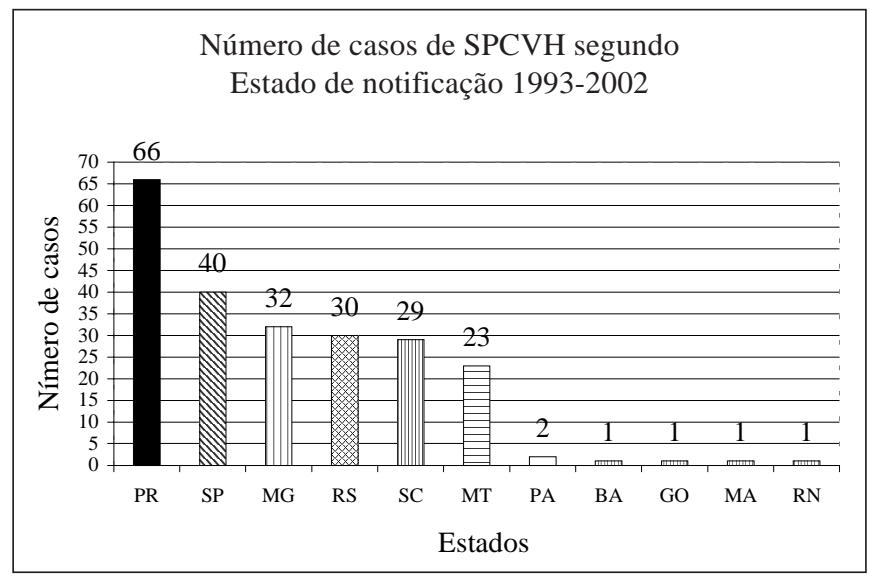

Figura 4 - Distribuição dos casos de SPCVH no Brasil, segundo o Estado de notificação

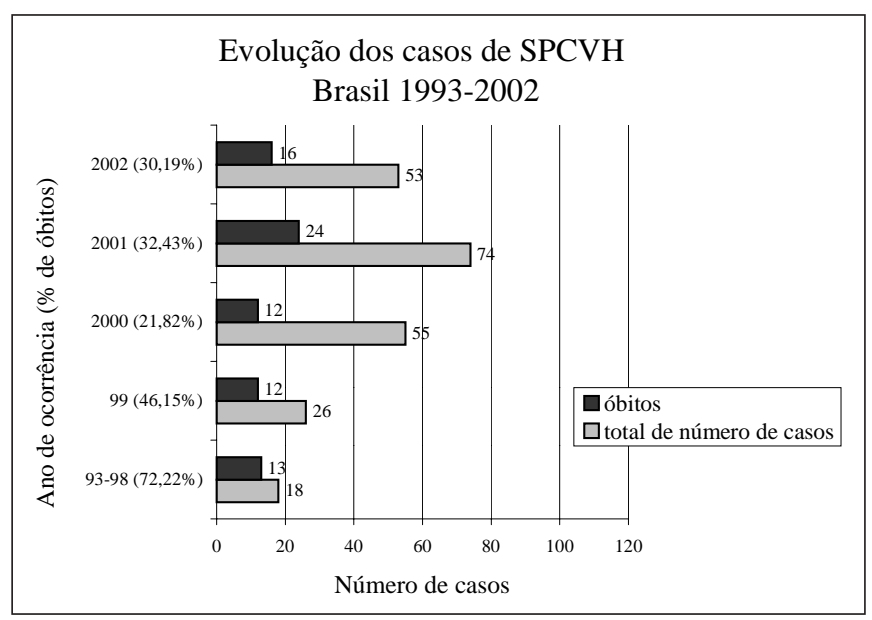

Figura 5 - Evolução dos casos de SPCVH no Brasil 
entenda seu surgimento. São importantes o estudo geográfico e histórico da região, sua ocupação espacial, as estruturas de trabalho e produção, o padrão migratório, a composição étnica, a dinâmica do comportamento dos roedores e suas relações com os diferentes vírus, além de alterações do ecossistema e de seus determinantes ambientais. ${ }^{(20,28,31-33,40)}$ Estudos com captura de roedores silvestres no Estado de São Paulo mostraram que Akodon $\mathrm{sp}$ (rato da mata), Oligoryzomys sp (ratinho do arroz) e principalmente Bolomys lasiurus (rato do rabo peludo) têm sido encontrados apresentando anticorpos séricos para hantavírus e, provavelmente, seriam os reservatórios destes agentes causadores de SPCVH. $(25,28,31)$

A ocorrência de casos estaria associada a aumento populacional ou modificação comportamental das populações de roedores silvestres, provavelmente por desequilíbrio em seus nichos ecológicos causado pela atividade humana. No Estado de São Paulo, a maioria dos casos de SPCVH costuma ocorrer entre abril e julho, período que corresponde ao início da estação seca, ao início da safra da cana-de-açúcar, com queimadas em canaviais e, também, à época do aparecimento de sementes no capim braquiária, muito apreciadas como alimento pelos roedores silvestres. ${ }^{(28,31-34,41,42)}$ No Estado do Paraná determinouse que atividades agrícolas relacionadas ao Pinus constituem importante fator de risco para a aquisição da SP$\mathrm{CVH}$, que costuma ocorrer, predominantemente, no segundo semestre. ${ }^{(39)}$

Nos EUA, observou-se que algumas situações relacionam-se epidemiologicamente com a SPCVH e estão resumidos no Q uadro $1 .(3,11,26,29,30,43)$

\section{QUADRO 1}

\section{Situações relacionadas com a SPCVH}

- Aumento de roedores na habitação

- O cupação ou limpeza de locais previamente fechados onde haja infestação ativa por roedores

- Limpeza de silos ou outras construções externas

- Manipulação de excretas ou "ninhos" de roedores

- Residência ou visita a locais onde tenha havido aumento no número de roedores ou casos de SPCVH

- Manipulação de roedores sem utilização de luvas

- Conservação de roedores selvagens aprisionados como animais de estimação ou como objetos de pesquisa

- Manipulação de equipamentos e maquinaria estocados em locais infestados

- Exposição a dejetos de roedores em acampamentos e excursões

- Dormir ao relento, em contacto com o terreno

- Aragem ou plantio manual
$\mathrm{N}$ as condições ambientais os vírus provavelmente sobrevivem por período menor que uma semana em ambientes internos e por período menor ainda se expostos à luz do sol, em áreas externas. ${ }^{(42,43)}$

Os hantavírus brasileiros associados à SPCVH foram detectados principalmente por amplificação de parte do genoma utilizando a RT-PCR (reação em cadeia de polimerização com a transcriptase reversa). Os fragmentos genômicos virais tiveram seus nucleotídeos seqüenciados e comparados com os de outros hantavírus, previamente conhecidos, em análises filogenéticas. A nalisados por essa metodologia, os vírus Araraquara e Castelo dos Sonhos mostraram homologia genômica de $78,5 \%$ quando comparados com os vírus sul-americanos Andes e Laguna Negra, confirmando assim ser realmente hantavírus. ${ }^{(25)}$ A lém disso, os vírus Araraquara e Castelo dos Sonhos mostraram entre si uma homologia genômica de 78,9 a $82,8 \%$, sugerindo ser dois vírus distintos que circulam no país em regiões distantes, possivelmente com diferentes roedores-reservatório. (25)

Seqüências nucleotídicas de amplicons obtidos por RTPCR a partir do sangue de casos da SPCVH ocorridos na região de Ribeirão Preto, SP, mostraram alta homologia com o hantavírus Araraquara $(87,7 \%$ a 96,5\%), sugerindo ser este 0 vírus responsável pela doença naquela região. ${ }^{(44)}$

Curiosamente, estudos soroepidemiológicos analisando os níveis de infecção por hantavírus na população da região de Ribeirão Preto, SP, não corroboraram os dados epidemiológicos, observados nos pacientes com SPCVH, que mostram clara ligação com atividades ou contato com o meio rural. Em 1999, realizou-se inquérito sorológico que detectou anticorpos IgG contra antígenos recombinantes da proteína $\mathrm{N}$ do vírus Sin Nombre por método de ELISA, no qual se testaram 567 soros, com o achado de positividade em $1,23 \%$ deles. ${ }^{(45)}$ Tais resultados sugerem não ser rara a infecção por hantavírus, na região de Ribeirão Preto, sendo sua freqüência mais que duas vezes maior do que a observada nos Estados U nidos, em populações com alto risco de infecção por estes microorganismos. ${ }^{(3,43)}$

Também foi possível entrevistar seis dos sete pacientes que apresentaram anticorpos para hantavírus, neste inquérito sorológico, observando-se que todos negaram doenças pulmonares graves pregressas. Sugere-se, por essa observação, que a hantavirose possa produzir infecções humanas, manifestas de forma subclínica ou de forma mais branda que as originalmente descritas na região. ${ }^{28,}$ $32,33,41,44-46)$

Em 2001, dando continuidade a este estudo, realizouse inquérito sorológico aleatório populacional no município de Jardinópolis. Participaram do estudo 818 indivíduos com 15 a 70 anos de idade. O bservou-se que 14,3\% 
dos participantes apresentavam anticorpos IgG para 0 hantavírus Andes detectado por ELISA. ${ }^{(32,46)}$ Não se observou predominância de soropositividade associada a sexo, idade, referência a contato com roedores ou antecedente de pneumonia grave. Esses resultados fazem supor que infecções por hantavírus sejam freqüentes, na região do estudo e, possivelmente, também em outras regiões do país. Esses resultados também poderiam indicar a coexistência de outro tipo de hantavírus, que causaria infecções humanas de menor gravidade ou subclínicas, que não seriam suspeitadas ou diagnosticadas. $\mathrm{O} u$, ainda, poder-seia supor ser a doença grave, SPCVH, uma forma mais rara e determinada por algum fator, talvez genético, presente em uma minoria de indivíduos, dentro do vasto contingente de infectados. ${ }^{(32,42,44-46)}$

\section{Manifestações CLÍNICAS}

A pesar de no Brasil contabilizarmos mais de duas centenas de casos da SPCVH, apenas algumas séries clínicas foram relatadas. $(32,33,37,47,48) \cup$ tilizaremos como casuística o somatório destas séries, de forma a melhor analisar o quadro clínico da SPCVH em nosso meio. Ressaltamos a série de 14 pacientes estudados em Ribeirão Preto( ${ }^{(32,33)} \mathrm{e}$ outra incluindo oito casos provenientes de U beraba. ${ }^{(47)}$ Também os três pacientes iniciais de J uquitiba ${ }^{(37)}$ e um caso de A najatuba( ${ }^{(48)}$ serão considerados de forma a traçar as semelhanças e peculiaridades da apresentação da SPCVH no Brasil.

\section{Período de INCUBAÇÃo}

0 estudo de pacientes com exposição bem definida e isolada a roedores permitiu estabelecer o período de incubação da SPCVH entre nove e 33 dias, com mediana de 14 a 17 dias. Também, determinaram-se atividades e comportamentos de risco para a aquisição da doença. ${ }^{(49)}$

\section{FASE PRODRÔMICA}

A evolução da SPCVH mostrou-se similar na maioria dos pacientes relatados no Brasil. Os sinais e sintomas no início do quadro incluíam febre, astenia e cefaléia. $\mathrm{Na}$ fase prodrômica os pacientes não apresentavam tosse, coriza, ou outros sintomas respiratórios. Também nesta fase, ocorriam calafrios, náuseas e vômitos, não sendo incomum a dor abdominal e a diarréia.

Nos EUA, em série de 44 pacientes relatados por Zaki et al. ${ }^{(50)}$ a duração do pródromo febril foi de três dias em média, e precedeu a procura de auxílio médico. Os sintomas mais freqüentemente relatados também foram febre e mialgia. Transtornos gastrointestinais como náuseas, vômitos e dores abdominais ocorreram em cerca de $50 \%$ dos casos. Nas epidemias de SPCVH causadas pelo vírus Andes, na A rgentina, também observaram-se pródromos com febre, mialgia e queda do estado geral. Nesses pacientes, os sintomas gastrointestinais mostraram-se mais $\operatorname{raros}(5 \%) .(20,22,23)$

A mialgia nos casos brasileiros, ao contrário do observado nos causados pelo vírus Sin Nombre, ${ }^{(51)}$ esteve presente em apenas $38 \%$ dos casos. ${ }^{(32,33)}$

$\mathrm{Na}$ fase prodrômica ocorre viremia e os níveis de antígenos são tão elevados como na AIDS e na hepatite C, mas, apesar disso, é difícil o isolamento de hantavírus a partir de materiais biológicos provenientes de seres humanos. ${ }^{(52,53)}$

\section{FASE CARDIOPULMONAR}

A pós o terceiro dia de doença, surge, geralmente, tosse seca, que posteriormente se torna produtiva, com escarro róseo, mucossanguinolento e dispnéia, que inicialmente é de leve intensidade, mas que na maioria dos casos, em menos de 24 horas, evolui para insuficiência respiratória grave, necessitando muitas vezes da instituição de suporte ventilatório ${ }^{(3,32-34,42,51)}$ (Tabela 1).

Nos casos ocorridos no Brasil, a dispnéia aos mínimos esforços ou de repouso acompanhava-se de tosse com eliminação de secreção rósea, estertoração pulmonar, taquicardia e hipotensão arterial, seguidas por colapso cardiocirculatório. Nesta fase da doença, além da hipoxemia, eleva-se o hematócrito, observa-se leucocitose com desvio à esquerda, linfócitos anormais ao esfregaço de sangue periférico e ocorre plaquetopenia. Também elevam-se os níveis de creatinina sérica, geralmente por diminuição do fluxo sanguíneo renal. ${ }^{32-34,47)}$

0 aparecimento do edema agudo de pulmões e da depressão miocárdica, nos pacientes com SPCVH, associamse à intensa reação imunológica com produção de anticorpos neutralizantes do vírus e, também à ativação da resposta celular com liberação de citocinas, fator de ativação plaquetária (PAF) e fator de necrose tumoral (TNF).(52-54)

As anormalidades laboratoriais observadas incluem, principalmente: elevação do hematócrito, leucocitose com desvio à esquerda, linfócitos anormais ao esfregaço e plaquetopenia. Pode ocorrer elevação moderada das enzimas ALT (alanina-transaminase) e DHL (desidrogenase láctica). $(18,32-34,51)$

As formas de infecção por hantavírus na América do Sul incluem apresentações clínicas que variam de infecções assintomáticas e formas leves de doença à SPCVH. A ocorrência de acometimento renal foi observada em muitos casos. Entre $30 \%$ e $70 \%$ dos casos causados por vírus Andes apresentaram transtornos hemorrágicos de magnitude variável e $6 \%$ desenvolveram insuficiência renal, necessitando de diálise transitória. ${ }^{(20-22)}$ 
Q uanto às formas mais graves de acometimento cardiopulmonar, Crowley et al., em 1998, através da análise retrospectiva dos casos tratados no Hospital Universitário da Universidade de Novo México (centro de referência para os pacientes da região de Four Corners), determinaram que a presença de qualquer um dos seguintes achados: índice cardíaco $<2,5 \mathrm{~L} / \mathrm{min} / \mathrm{m}^{2}$, concentração de lactato sérico $>4,0 \mathrm{mmol} / \mathrm{L}$, atividade elétrica cardíaca sem pulsação ou fibrilação ventricular ou taquicardia ventricular, e choque refratário à administração de volume e de aminas vasoativas, relacionava-se com mortalidade de $100 \%$. ${ }^{(55)}$

\section{FASE DE CONVALESCENÇA}

A convalescença dos pacientes com SPCVH, especialmente daqueles que necessitaram de intubação orotraqueal com ventilação mecânica, costuma ser prolongada, levando algumas semanas, principalmente devido à espoliação nutricional conseqüente à doença grave e, também, conseqüente a pneumonias hospitalares. $(3,18,33,34)$

A avaliação médica tardia dos casos de SPCVH tem mostrado seqüelas como fadiga crônica e restrição da função pulmonar, com repercussões na qualidade de vida de mais que $30 \%$ dos pacientes na A mérica do Norte. ${ }^{(56)}$
No Brasil, dois pacientes que sobreviveram à SPCVH, de ambos os sexos e com 16 anos e 31 anos, foram ambos reavaliados, 30 meses após o quadro agudo. Eles não referiram nenhuma intercorrência ou queixa após a alta hospitalar. Ao exame clínico não se evidenciou nenhuma alteração patológica. Tomografias de tórax de ambos os pacientes foram normais e testes de função pulmonar também mostraram resultados dentro dos limites da normalidade. (32)

\section{DiAgNÓSTICO DIFERENCIAL}

Fazem diagnóstico diferencial com a SPCVH: as pneumonites virais, como a por Influenza e pelo Sarampo, as pneumonias atípicas por Micoplasma e Legionelose, a Leptospirose, Febre Q, Tularemia, a Peste Septicêmica, a H istoplasmose, Dengue Hemorrágico e, nos pacientes imunocomprometidos, a pneumonia por Pneumocystis carinii e as infecções por citomegalovírus, Cryptococcus e Aspergillus. ${ }^{(5,8,18,33,34,51)}$

A ausência de sintomas nasais como rinorréia, espirros e obstrução, durante a fase prodrômica, facilita o diferencial com viroses respiratórias altas.

Em nosso meio, a pneumonia por Pneumocystis carinii como primeira manifestação da AIDS e o Dengue He-

TABELA 1

Apresentação clínica e desfecho dos casos de SPCVH relatados no Brasil

\begin{tabular}{|c|c|c|c|c|c|c|c|}
\hline $\begin{array}{l}\text { Paciente/ } \\
\text { série }\end{array}$ & Sexo & Idade & $\begin{array}{c}\mathrm{SaO}_{2} \underset{(\%)}{\text { inicial AA }} \\
\text { (\%) }\end{array}$ & $\begin{array}{c}\text { Choque/ } \\
\text { hipotensão }\end{array}$ & $\begin{array}{c}\text { Suporte } \\
\text { ventilatório }\end{array}$ & $\begin{array}{c}\text { U so de } \\
\text { AVA }\end{array}$ & Evolução \\
\hline JQT1 & $M$ & 18 & $\mathrm{NI}$ & $\mathrm{N}$ & $\mathrm{N}$ & $\mathrm{N}$ & Cura \\
\hline JQT2 & $M$ & 20 & $\mathrm{NI}$ & $\mathrm{S}$ & VM & $\mathrm{S}$ & Ó bito \\
\hline JQT3 & $M$ & 16 & $\mathrm{NI}$ & $S$ & VM & $\mathrm{NI}$ & Ó bito \\
\hline RP1 & $M$ & 55 & 61 & $S$ & VM & $\mathrm{S}$ & Ó bito \\
\hline RP2 & $M$ & 38 & 53 & $S$ & VM & $S$ & Ó bito \\
\hline RP3 & $M$ & 54 & 96 & $\mathrm{~N}$ & VM & S & Ó bito \\
\hline RP4 & $M$ & 26 & $\mathrm{NI}$ & $\mathrm{S}$ & VM & $S$ & Ó bito \\
\hline RP5 & $M$ & 29 & 71 & S & VM & S & Cura \\
\hline RP6 & $\mathrm{F}$ & 13 & 72 & S & VM & $\mathrm{S}$ & Cura \\
\hline RP7 & $M$ & 21 & 82 & $\mathrm{~S}$ & VM & $\mathrm{S}$ & Cura \\
\hline RP8 & $M$ & 32 & 73 & $\mathrm{~N}$ & VMF & $\mathrm{N}$ & Cura \\
\hline AN J1 & $\mathrm{F}$ & 19 & $\mathrm{NI}$ & $\mathrm{NI}$ & $\mathrm{NI}$ & $\mathrm{NI}$ & Ó bito \\
\hline UB1 & $M$ & 45 & $<90 \%\left(\mathrm{paO}_{2}=55\right)$ & $\mathrm{S}$ & VM & $\mathrm{S}$ & Ó bito \\
\hline UB2 & $\mathrm{F}$ & 22 & $<90 \%\left(\mathrm{paO}_{2}=40\right)$ & $S$ & VM & $S$ & Ó bito \\
\hline UB3 & $M$ & 19 & $<90 \%\left(\mathrm{paO}_{2}=48\right)$ & S & VM & S & Ó bito \\
\hline UB4 & $M$ & 47 & $<90 \%\left(\mathrm{paO}_{2}=48\right)$ & $\mathrm{N}$ & $M F$ & $\mathrm{~N}$ & Cura \\
\hline U B5 & $M$ & 62 & $<90 \%\left(\mathrm{paO}_{2}=50\right)$ & $\mathrm{S}$ & VM & $\mathrm{S}$ & Ó bito \\
\hline UB6 & $M$ & 24 & $<90 \%\left(\mathrm{paO}_{2}=49\right)$ & S & $M F$ & S & Cura \\
\hline U B7 & $M$ & 26 & $<90 \%\left(\mathrm{paO}_{2}=57\right)$ & S & MF & S & Cura \\
\hline UB8 & $M$ & 32 & $<90 \%\left(\mathrm{paO}_{2}=49\right)$ & S & $M F$ & $\mathrm{~N}$ & Cura \\
\hline
\end{tabular}

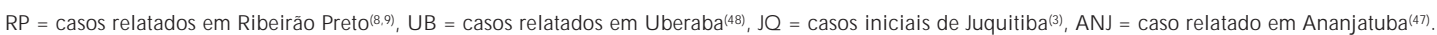
$\mathrm{M}=\mathrm{M}$ asculino; $\mathrm{F}=$ Feminino; $\mathrm{NI}=\mathrm{N}$ ão informado; $\mathrm{S}=\operatorname{sim}$, presença; $\mathrm{N}=$ não, ausência; $\mathrm{AA}=\mathrm{Ar}$ ambiente; $\mathrm{AVA}=\mathrm{Aminas}$ vasoativas; $\mathrm{VM}=\mathrm{Ventilação}$ mecânica; $M F=$ nebulização de ar enriquecido em $\mathrm{O}_{2}$ por máscara facial. 


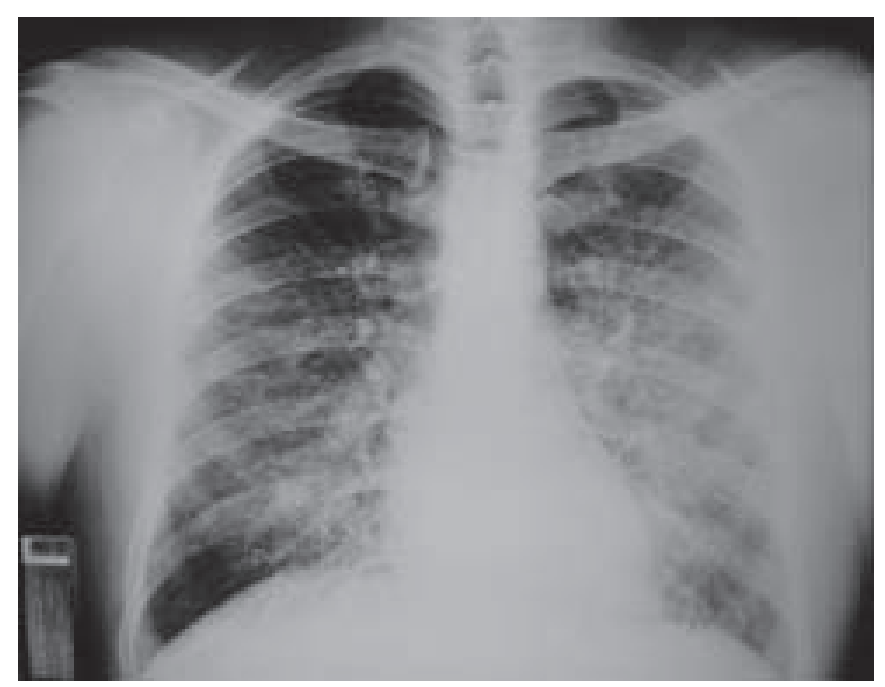

Figura 6 - Radiografia de tórax de paciente com SPCVH, mostrando o infiltrado intersticial inicial

morrágico em casos com derrame pleural mostram-se importantes doenças para o diagnóstico diferencial com SPCVH. ${ }^{(32-34)}$

\section{A PRESENTAÇÕES ATÍPICAS}

Recentemente, Passaro et al. descreveram um caso de pielonefrite que posteriormente evoluiu com insuficiência respiratória e óbito, sendo confirmado o diagnóstico de SPCVH pelo vírus Sin Nombre, através de sorologia positiva e seqüenciamento gênico viral, realizado pelo CDC. ${ }^{(57)}$

Zavasky et al., em 1999, publicaram o relato de dois casos em que a infecção pelo vírus Sin Nombre não causou alterações respiratórias, alertando para a possibilidade de um mais amplo espectro da doença. ${ }^{(58)}$

Em nosso meio, como se pode inferir pelos inquéritos sorológicos populacionais e à semelhança do que ocorre em outros países da América do Sul, (21,27) deve haver formas mais brandas ou subclínicas da doença, que não são diagnosticadas. $32,42,45,46)$

\section{DiAgNÓSTICO RADIOLÓGICO}

A caracterização e o reconhecimento das alterações radiológicas da SPCVH são importantes na identificação e auxiliam, ainda, na determinação do prognóstico da síndrome. (59)

Já em 1994, Ketai et al. publicaram estudo de uma série de 16 pacientes com quadro clínico e confirmação laboratorial de SPCVH, ${ }^{(60)}$ conforme definição do $C D C .{ }^{(61)}$ Em 13 desses pacientes (88\%) foram observadas alterações radiológicas indicativas de edema intersticial na radiografia de tórax inicial, como: presença de linhas B de Kerley, espessamento peribronquiolar e borramento do

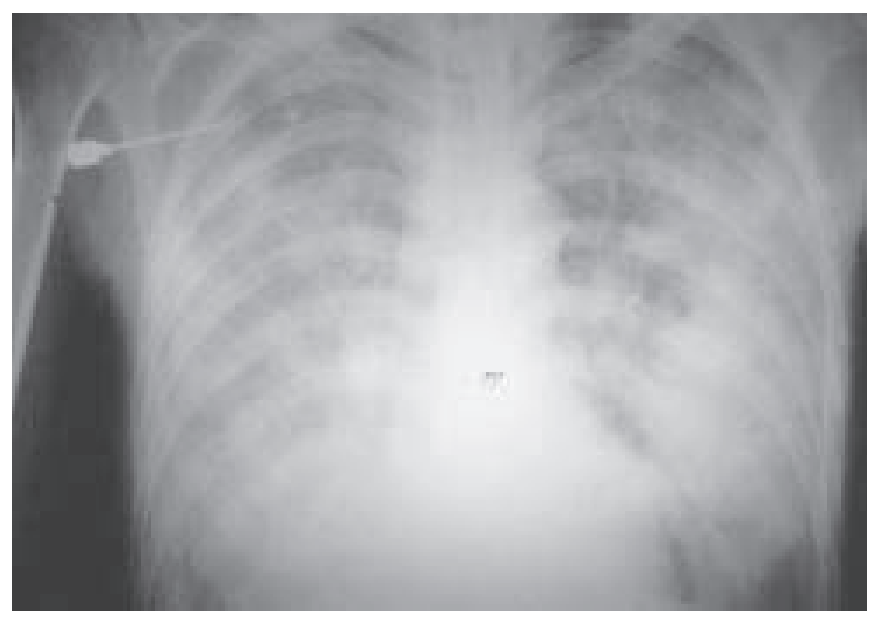

Figura 7 - Radiografia de tórax de paciente com forma grave de SPCVH mostrando infiltrados alveolares bilateralmente

contorno hilar pulmonar (Figura 6). Tais alterações são menos evidentes na SDRA e ajudam no diagnóstico diferencial. ${ }^{(62,63)}$

O utros três pacientes apresentavam radiografias de tórax inicialmente normais mas, nas 48 horas subseqüentes, desenvolveram-se sinais de edema intersticial em todos os pacientes. ${ }^{(60)}$

Q uatro pacientes manifestaram primordialmente doença intersticial durante todo o curso da doença e todos sobreviveram, ${ }^{(60)}$ indicando que a não progressão para preenchimento alveolar pode ser um marcador de meIhor prognóstico na SPCVH.

Seis pacientes possuíam radiografia de tórax inicial com alterações de preenchimento alveolar. A pós as primeiras 48 horas, 11 pacientes apresentaram infiltrados alveolares bilaterais e extensos (assim considerados quando envolvendo mais da metade de ambos os campos pulmonares). Todos esses pacientes apresentaram quadro de desconforto respiratório, oito necessitaram suporte ventilatório artificial e seis faleceram, ${ }^{(60)}$ indicando pior prognóstico nas formas extensas do acometimento alveolar (Figura 7).

Também todos os pacientes possuíam índice cardiotorácico menor que $55 \%$, portanto, sem sinais de aumento das câmaras cardíacas. 0 pedículo vascular encontravase de tamanho normal em 14 pacientes $^{(60,62)}$ (considerada espessura normal de até $5,3 \mathrm{~cm}$ na radiografia em pé e até $6,3 \mathrm{~cm}$ nas radiografias em posição supina $\left.{ }^{(64)}\right)$.

Efusão pleural também é comum. Na série relatada esteve presente em 11 pacientes. Era já visível na radiografia inicial em dois e desenvolveu-se, nas primeiras 48 horas de observação, em nove pacientes. ${ }^{(60)}$

Como características distintivas da SDRA,(60) os autores salientaram a ausência de distribuição periférica do infiltrado alveolar e a presença de edema intersticial no início 
da SPCVH. Estudo anterior ${ }^{(63)}$ sobre alterações radiológicas na SDRA encontrou presença de espessamento peribronquiolar e linhas B de Kerley em menos de $10 \%$ de sua casuística. Também o aparecimento precoce de derrame pleural é raro na SDRA. (62-64)

0 preenchimento alveolar subseqüente aparece na maioria dos pacientes com hantavirose pulmonar e tende a ter distribuição basilar e peri-hilar ao invés de periférica, como mais freqüentemente observado na SDRA. ${ }^{(62,63)}$

Em recente estudo, realizado no Canadá por Boroja et al., não se observou mortalidade nos pacientes com formas não extensas de alterações radiográficas, em que houve predomínio de padrão intersticial ou interstício-alveolar. ${ }^{(59)}$

\section{DIAGNÓSTICO LABORATORIAL ETIOLÓGICO}

O diagnóstico laboratorial dos casos humanos de hantavirose, no Brasil, é comumente feito por método sorológico de ELISA, que visa a detecção de anticorpos principalmente do tipo IgM, associados a infecção recente. Tal diagnóstico é possível, mesmo na fase aguda da doença, porque os anticorpos, na SPCVH, surgem com o aparecimento dos sinais e sintomas. $(2,3,23,27,33,34,43)$

Métodos sorológicos que detectam anticorpos específicos, do tipo lgG, têm sido mais utilizados em inquéritos populacionais. Utilizam-se, nesses testes, antígenos dos hantavírus Sin Nombre ${ }^{(65)}$ (EU A) ou Andes (A rgentina). ${ }^{(66)}$ Esses antígenos são produzidos por purificação direta do material viral, após inativação ou, preferencialmente, são proteínas recombinantes produzidas em bactérias, como a N ou a G1 da superfície viral. A mbas são importantes antígenos virais.

O utros métodos sorológicos menos utilizados no diagnóstico das hantaviroses são: a imunofluorescência indireta com células infectadas por hantavírus em spot-slides e o Western blot. ${ }^{(67)}$

A metodologia de RT-PCR, que detecta o genoma de hantavírus em materiais clínicos, mostra-se extremamente útil e prática para o diagnóstico da SPCVH. Trata-se de metodologia simples, de rápida realização e que pode ser feita em laboratórios sem condições especiais de segurança, as quais são recomendadas para 0 isolamento de hantavírus em culturas celulares. ${ }^{(3,43)}$ Para a RT-PCR, extrai-se o RNA do sangue total ou soro do paciente. Materiais provenientes de roedores também podem ser processados dessa forma. Em seguida, utilizando o extrato de RNA do material clínico, guiado por iniciador (primer) específico para uma região do genoma de hantavírus e com auxílio da enzima transcriptase reversa (RT), transforma-se o fragmento de genoma viral em DNA complementar e, este, por sua vez, orientado por um par de primers, é amplificado milhões de vezes pela reação em cadeia da polimerase ( $P C R)$, em ciclos térmicos que utilizam a enzima termorresistente TaqDNA polimerase. A presença do segmento genômico viral amplificado pode, assim, ser detectada por uma simples reação de leitura química.

Para a realização de RT-PCR, deve-se encaminhar ao laboratório o material clínico em, no máximo, 12 horas após a coleta. As amostras devem ser conservadas à temperatura de geladeira comum $\left(4^{\circ} \mathrm{C}\right)$ durante seu transporte. Também podem-se armazenar amostras, por longos períodos, em nitrogênio líquido ou em "freezers" a $-70^{\circ} \mathrm{C}$.

$O$ produto amplificado da PCR pode ter seus nucleotídeos seqüenciados e, por comparação com genomas conhecidos de hantavírus, pode-se obter informação sobre qual é o vírus causador do quadro ou pode-se determinar seu relacionamento filogenético com outros microorganismos do mesmo gênero, inclusive permitindo inferências quanto a seus roedores-reservatório. $(3,25,27,28)$

Todos os hantavírus causadores de SPCVH, no Brasil, tiveram seu genoma detectado por RT-PCR, não tendo havido isolamento viral em cultivo celular. ${ }^{(25,28,44)}$

A análise filogenética dos hantavírus das A méricas mostra que os vírus brasileiros J uquitiba, Castelo dos Sonhos, Araraquara são muito semelhantes a outros hantavírus sul-americanos, particularmente ao vírus argentino Andes e ao Laguna Negra. ${ }^{(25)}$

0 isolamento de hantavírus deve ser realizado em laboratório com equipamentos de segurança de nível 3 , que protegem contra eventuais acidentes nos quais o microorganismo possa sair do recinto onde os materiais contaminados estão sendo processados e, também, protegem os trabalhadores do laboratório quanto à contaminação com estes microorganismos. ${ }^{(43,44)} \mathrm{O}$ isolamento viral, a partir de materiais biológicos de pacientes com SPCVH ou de roedores, costuma ser feito por inoculação destes materiais em cultura de células de rim de macaco verde africano: VERO-E6. Os vírus, assim eventualmente isolados, podem ser identificados por métodos de imunofluorescência ou de RT-PCR. ${ }^{(43,44,67,68)}$

\section{DiAgNÓSTICO LABORATORIAL}

Como os métodos de diagnóstico definitivos para SPCVH, a saber, sorológicos e de detecção viral, não se encontram disponíveis em laboratórios de análise comuns, as alterações laboratoriais mais freqüentemente encontradas nos pacientes com SPCVH podem e devem servir como um indicador de alta suspeição para a doença. ${ }^{(3,18,27,32-34)}$

Koster et al., em 2001, publicaram um estudo de 52 pacientes com SPCVH confirmada por testes sorológicos específicos. A nalisaram o esfregaço de sangue periférico desses pacientes, comparando-os com 128 esfregaços em que a sorologia para SPCVH resultou negativa. M ostraram 
que, durante a fase prodrômica, a plaquetopenia é a única anormalidade consistentemente observada, devendo ser interpretada como uma indicação para a realização das provas sorológicas específicas. ${ }^{\left({ }^{69)}\right.}$ A dicionalmente determinaram que o encontro de quatro das cinco seguintes características apresentadas no Quadro 2 fazia com que se diagnosticasse a SPCVH com sensibilidade de $96 \%$ e

\begin{tabular}{|l|}
\multicolumn{1}{c|}{ Q U AD RO 2} \\
Alterações laboratoriais mais freqüentes \\
encontradas nos pacientes com SPCVH
\end{tabular}

especificidade de $99 \%$, não havendo falso-negativos entre os pacientes que futuramente evoluíram com formas mais graves, necessitando de internação em UTI. Determinaram também que a plaquetopenia era o único achado, consistentemente observado, durante a fase prodrômica da doença. ${ }^{(69)}$

Baseados nesse estudo e também nos dados epidemiológicos das alterações mais freqüentemente encontradas nos pacientes, em nosso meio, Figueiredo et al. ${ }^{(5,9,43)} \mathrm{e}$ Campos et al. ${ }^{(32,46)}$ desenharam um fluxograma para a presunção diagnóstica da SPCVH (Figura 8).

A decisão de internação em ambiente de terapia intensiva tem-se mostrado importante na determinação da sobrevida dos pacientes. Assim, tenta-se rastrear precocemente os casos de provável pior evolução clínica, para disponibilizar-Ihes os suportes adequados de UTI.

Como anteriormente citado, o padrão radiológico de acometimento alveolar extenso determina mau prognóstico clínico, ${ }^{(59,60)}$ bem como os quadros de falência hemodinâmica. ${ }^{(55)}$

Talvez um marcador precoce de gravidade possa ser a determinação da carga viral: Terajima et al., em 1999, desenvolveram um ensaio quantitativo utilizando a técnica de reação de polimerização em cadeia (PCR), direcionada à transcriptase reversa viral, demonstrando a presença de grande número de partículas virais no sangue de

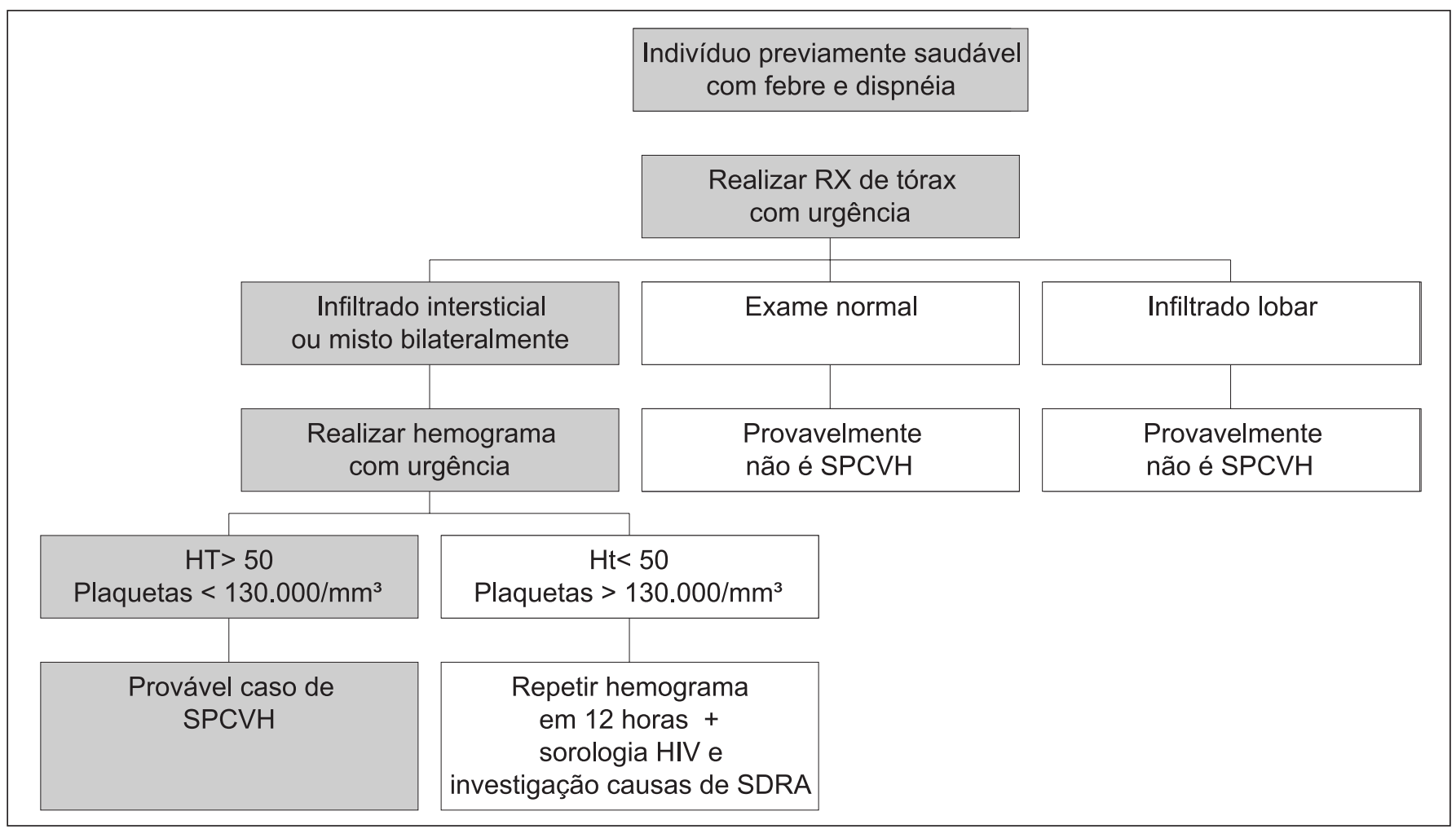

Figura 8 - Fluxograma para diagnóstico de SPCVH no Brasil 
pacientes que desenvolveram SPCVH, especialmente nos casos mais graves e fatais. Nos que sobreviveram, o número de partículas virais decresceu paralelamente à resolução da febre. ${ }^{(53)}$

\section{DiAgNÓSTICO ANATOMOPATOLÓGICO}

Materiais da necropsia de casos fatais da SPCVH, como fragmentos de pulmão e outros órgãos, podem ser processados por método imunohistoquímico e de hibridação visando a detecção da presença do hantavírus, através de sua visualização em microscópio. Também pode-se detectar o genoma viral em tecidos por RT-PCR. ${ }^{(50,70)}$

Estudos realizados logo após o surto inicial, nos EUA, conseguiram determinar as principais características patológicas da síndrome. ${ }^{(51,70)}$ Nesses estudos, amostras teciduais de pacientes com SPCVH foram examinadas através de técnica imunohistoquímica utilizando anticorpos monoclonais específicos (especialmente GB04-BF07, que reage com todos os sorotipos de hantavírus conhecidos) e anticorpos policlonais do soro de pacientes convalescentes.

Zaki et al. observaram 44 casos fatais de SPCVH. Determinaram que há envolvimento de múltiplos órgãos com graus variáveis de congestão vascular. A principal característica histopatológica, no entanto, foi o acometimento pulmonar por uma pneumonite de intensidade leve a moderada, presente em 40 dos 44 casos. Observaram graus variáveis de edema, congestão vascular e infiltrado mononuclear. Também, caracteristicamente, houve ausência de trombos vasculares e de necrose ou alterações morfológicas de células endoteliais. 0 epitélio respiratório encontrava-se intacto, sem que se observassem alterações nos pneumócitos tipo I, sem evidências de debris celulares, fragmentação nuclear ou hiperplasia de pneumócitos II. (50)

As células endoteliais também encontravam-se intactas, mas partículas virais eram freqüentemente observadas em seu interior. As paredes alveolares pareciam espessadas pela presença de abundante material proteináceo extravasado e eritrócitos. No interior dos alvéolos podese observar grande quantidade de fluido e raras membranas hialinas, mas o infiltrado celular intra-alveolar e debris celulares, típicos da SDRA, estavam ausentes na SPCVH. ${ }^{(50,70)}$

O infiltrado celular mononuclear era composto por células de volume aumentado, com aparência de imunoblastos. A caracterização do tipo celular foi realizada em cinco pacientes e mostrou ser uma mistura de linfócitos $T$ ativados (CD3+) e células de linhagem monocítica/ macrofágica (KP1 e Ki-M1P +), com pouca contribuição de neutrófilos para o infiltrado celular. ${ }^{(50)}$

A presença do infiltrado imunoblástico, típico da SPCVH, é importante no diagnóstico diferencial com a AIP (acute interstitial pneumonia). Na AIP também se podem observar evidências histológicas de organização e seu curso clínico geralmente é mais prolongado e protraído. ${ }^{(71)}$

A presença de imunoblastos também é freqüente no baço, especialmente na polpa vermelha e no espaço periarteriolar, e em linfonodos, na região paracortical e sinusoidal. ${ }^{(50,70)} \mathrm{A}$ medula óssea apresenta-se com moderado aumento de celularidade, com proeminente desvio à esquerda na mielopoiese. ${ }^{(50)}$

\section{FISIOPATOLOGIA}

Nos estudos de anatomopatologia conseguiu-se determinar que há um tropismo viral pelas células endoteliais, sendo observadas partículas virais por métodos histoquímicos e por microscopia eletrônica em células do endotélio capilar em vários tecidos. A microscopia eletrônica também demonstrou a pobreza de efeitos citopáticos nessas células.

A principal alteração observada na SPCVH é o aumento da permeabilidade vascular, que explicaria o edema pulmonar, a hemoconcentração e o colapso circulatório encontrados na síndrome. ${ }^{(51,70,71)}$

Nos pulmões postula-se que o epitélio alveolar, permanecendo intacto, retarda o preenchimento dos espaços alveolares, mantendo grande parte do líquido extracelular no interior do interstício pulmonar, explicando a proeminência de edema intersticial com linhas $B$ de Kerley e espessamento peribronquiolar, observados inicialmente à radiografia de tórax ${ }^{(50,60)}$ (Figura 6 ).

NaS FHSR, por outro lado, há predominância de alterações vasculares no compartimento retroperitoneal, incluindo os rins. ${ }^{(71)}$

A mbas as doenças humanas causadas por hantavírus, a SPCVH e a FHSR, resultariam de defeitos na função endotelial e plaquetária. A patogênese desses defeitos parece ser mediada pela interação entre as glicoproteínas virais e beta-3-integrinas presentes nas células endoteliais e em plaquetas. ${ }^{(32-34,72,73)}$ Pelo fato das beta-3-integrinas consistirem de receptores críticos de adesividade em plaquetas e em células endoteliais, e por regularem a permeabilidade vascular e a adesão e ativação plaquetárias, é provável que a utilização desses receptores pelos hantavírus seja fundamental para a determinação de seus efeitos patogênicos. ${ }^{(72,73)}$

A resposta imune humoral parece ser importante na determinação da sobrevida. Há resposta precoce com a produção de IgM, IgA e IgG. O pico de detecção de lgM coincide com um a dois dias do estabelecimento dos sintomas e o pico de IgG ocorre na primeira semana da doença, enquanto que a IgA tem sua resposta máxima por volta do 15 o dia. Ausência ou baixos títulos de IgG foram associados a maior taxa de mortalidade.(23) 
Técnicas de coloração imunohistoquímica têm sido realizadas para o estudo de material de necropsia de pacientes falecidos por SPCVH. Mori et al., em 1999, descreveram o encontro de grande número de células produtoras de citocinas (monocinas: IL-1-alfa, IL-1-beta, IL-6 e TNF-alfa; linfocinas: interferon-gama, IL-2, IL-4 e TNF-beta) em pulmões e baço de pacientes falecidos em decorrência da SPCVH, o que sugere que a produção local de citocinas tenha papel importante na patogênese da síndrome. Em contraste, os autores observaram pequena quantidade ou ausência de células produtoras de citocinas em pulmões de pacientes falecidos por SDRA e outras patologias. ${ }^{(54)}$

\section{TRATAMENTO DE SUPORTE}

Vale a pena ressaltar que a suspeita clínica e o conhecimento das manifestações precoces da síndrome são essenciais para que se transfira o paciente precocemente para a unidade de terapia intensiva, pois a probabilidade de sobrevida aumenta com a adoção de medidas agressivas de suporte cardiorrespiratório. $(3,18,27,32-34)$

A assistência ventilatória e a hemodinâmica são cruciais nos casos mais graves. Geralmente são necessárias a intubação traqueal e a ventilação mecânica com pressão positiva.

0 ajuste hemodinâmico também tem grande importância e, nos casos de colapso circulatório concomitante à insuficiência respiratória, indica-se a monitorização através da instalação de cateter em artéria pulmonar (SwanGanz), para melhor documentar o perfil hemodinâmico da síndrome: baixo índice cardíaco e volume sistólico, pressão de artéria pulmonar ocluída normal ou baixa e alta resistência vascular periférica. ${ }^{(8,55)} \mathrm{A}$ monitorização hemodinâmica também é útil na criteriosa reposição volêmica e na adequação do suporte pressórico. $(3,8,18,27,32-34,55)$

A análise dos volumes infundidos por via parenteral em 10 pacientes com SPCVH mostrou haver associação significante ( $p=0,0152)$ entre volumes superiores a $2.500 \mathrm{ml}$, utilizados nas primeiras 24 horas de tratamento hospitalar, e a evolução para o óbito. ${ }^{(32)}$ Nesses pacientes, o líquido infundido tenderia a se concentrar nos pulmões, agravando, ainda mais, a insuficiência respiratória. ${ }^{(5,24,25,34)}$ A ssim, no contexto da SPCVH, é importante que a estabilização hemodinâmica seja realizada através da administração criteriosa de drogas vasoativas, preferindo-se a dobutamina, associada ou não à noradrenalina, por seus efeitos em resistência vascular periférica.

Q uanto à abordagem ventilatória, deve haver preferência pelas estratégias de proteção pulmonar, evitando-se a utilização de altas frações inspiradas de oxigênio e limitando-se à pressurização em vias aéreas para evitar a ocorrência de volu, baro e biotraumas. ${ }^{(74,75)}$

\section{TRATAMENTO ESPECÍFICO}

Com base em estudo clínico, realizado na China, de 1985 a 1987, que aplicou ribavirina endovenosa em 242 pacientes com FHSR por hantavírus, notando decréscimo de quatro vezes na mortalidade do grupo tratamento $(2 \%$ em 125 pacientes tratados $\times 8 \%$ em 117 pacientes tratados com placebo), tem-se utilizado esse medicamento para o tratamento da SPCVH, embora sua eficácia ainda não esteja estabelecida. ${ }^{(76)}$

A droga é eficaz in vitro contra os hantavírus, mas ainda não há comprovação dessa eficácia in vivo. Parece provável que a droga não tenha tempo de agir se administrada durante a fase clínica cardiopulmonar, em que predominam os mecanismos imunológicos. ${ }^{(76,77)}$

A tualmente, encontra-se em fase III um estudo aleatorizado, duplo-cego, placebo-controlado, comparando a efetividade da droga versus placebo no tratamento da SPCVH. A ribavirina, nesse estudo, é utilizada em maiores de 12 anos, em 15 doses de $16 \mathrm{mg} / \mathrm{kg}$, com periodicidade de seis em seis horas, após um bolus inicial com $30 \mathrm{mg} /$ $\mathrm{kg} \mathrm{e}$, posteriormente, nove doses administradas de oito em oito horas na posologia de $8 \mathrm{mg} / \mathrm{kg}$. 0 estudo é coordenado pelo CDC - EUA e, no momento, está ainda recrutando pacientes, não havendo resultados compilados. 0 principal efeito adverso consiste em anemia reversível com a interrupção da droga. ${ }^{(76)}$

\section{PreVEnÇÃo}

As estratégias de prevenção são de grande importância para o controle dessa grave síndrome. A erradicação dos hospedeiros roedores não é factível, nem desejável, pela alteração importante que esta medida poderia induzir em seu ecossistema. $(3,27,28,34,43)$

A maneira mais eficaz de diminuir o risco de SPCVH consiste em limitar a exposição humana aos roedores infectados ou a locais fechados onde haja infestação ativa por esses animais. O Centro de Prevenção e Controle de Doenças dos EUA (CDC - 2002) publicou recentemente orientações detalhadas dos cuidados para o controle de infestação de roedores e da doença. ${ }^{(43)}$

A publicação inclui orientações específicas para a prevenção de contacto com roedores, para a eliminação de infestações por esses animais, para a limpeza de áreas com dejetos ou roedores mortos e para o trabalho em locais onde houve infecção confirmada ou infestação grave por esses animais. ${ }^{(43)}$

De especial importância é a exposição peridoméstica, que pode ser evitada pela conservação da limpeza doméstica e de suas cercanias, pela construção de moradias à prova de roedores, com vedação de frestas em portas e nas entradas de encanamentos e fiações com mais de $6 \mathrm{~mm}$ de diâmetro. 
Em geral, suspeita-se de infestação por roedores pela observação direta de animais, pelo encontro de seus "ninhos" ou fezes (estas são pequenas e ovais como grãos de arroz e de coloração escura), ou ainda pela evidência de marcas de roedura em alimentos e outros objetos. ${ }^{27,28,32-}$ 34,43)

Nas áreas onde há relatos de casos, deve-se orientar a população sobre como limpar e lidar com dejetos e roedores mortos. Antes de entrar em locais infestados é aconselhável arejar 0 ambiente por algumas horas. Não se deve varrer ou aspirar os dejetos, pois isso causa maior aerolização das partículas. ${ }^{(3,34,43)}$

É importante também a orientação quanto à exposição recreacional a roedores, especialmente em acampamentos, excursões e atividades rurais. Não se deve dormir ao relento, nem sobre a grama, sem forrações ou tendas. Deve-se conservar o lixo em locais tampados e longe da barraca de camping. Os gêneros alimentícios devem permanecer guardados em recipientes vedados, para não atrair os roedores. ${ }^{(18,43)}$

Em residências localizadas em áreas infestadas é importante conservar pias e pratos sempre limpos, descartar o lixo em recipientes tampados e conservar caixas, roupas e outros objetos fora do contacto com o chão, para evitar que aí os ratos se aninhem. ${ }^{(43)}$

Nas habitações de área rural é interessante orientar para cuidados com o armazenamento de ração e água para animais, não deixando que permaneçam disponíveis no período da noite. Toda fonte de alimento para roedores deve ser removida das cercanias da residência, assim como lixo, veículos abandonados, pneus velhos, etc., que podem servir de local para que os roedores façam seus ninhos. Deve-se alertar para que áreas como hortas e viveiros de animais, assim como pilhas de lenha, tijolos, pedras e outros materiais, fiquem a, pelo menos, 50 metros de distância da residência. As áreas de armazenamento, como galpões e silos, devem ser vedadas para evitar a entrada de roedores e freqüentemente ventiladas. Não se deve armazenar colheitas ao ar livre. ${ }^{(3,18,32-34,43)}$

A utilização de ratoeiras e raticidas favorece o controle da população de roedores, nas áreas de infestação. Devese orientar para que as armadilhas sejam colocadas até uma semana após o aprisionamento do último rato. Para descartar as armadilhas e os animais aprisionados, é importante calçar luvas de látex ou vinil. Antes de coletar o material, deve-se embeber os dejetos ou os roedores mortos em solução de hipoclorito de sódio (solução 1:10 preparada no mesmo dia de sua utilização). Soluções detergentes ou comuns de limpeza também podem ser utilizadas, pois as partículas virais possuem envelope lipídico, sendo inativadas por esta medida. ${ }^{(43)}$

O material coletado deve ser colocado em embalagem plástica dupla e vedada. Para descartar o material, deve- se enterrá-lo em buracos com $70-90 \mathrm{~cm}$ de profundidade, ou queimá-lo, ou ainda colocá-lo em local tampado, apropriado para coleta regular de lixo. ${ }^{(18,43)}$

$N$ as áreas infestadas por roedores, deve-se proteger os seus predadores naturais, como cobras não venenosas e corujas. Em locais com infestação importante, além dos cuidados descritos acima, é importante acrescentar às precauções o uso de óculos de proteção e de máscaras com filtro de partículas aéreas de alta eficiência (high efficiency particulate arrest). Em áreas com infestação persistente é necessário, por vezes, contactar profissionais especializados no controle de pestes e roedores. ${ }^{(43)}$

$\mathrm{Na}$ região $\mathrm{O}$ este dos EUA, onde ocorre o risco de contaminação pela peste, através de pulgas, é importante a orientação do uso de repelentes em roupas, calçados e mãos antes de colocar as armadilhas para os roedores. ${ }^{(18,43)}$

As recomendações para o controle dos roedores e da infecção por hantavírus encontram-se pormenorizadas e atualizadas no site do CDC: All about hantavirus ${ }^{(18)}$ e podem ser fornecidas através do contacto com o CDC, National Center for Infectious Diseases (NCID), Special Pathogens Branch, e-mail: dvd1spath@cdc.gov.

É interessante ressaltar a possibilidade de transmissão interpessoal de vírus assemelhados ao Andes, devendose instituir precauções de isolamento respiratório e geral no cuidado com os pacientes, além das medidas universais de controle de infecções.

\section{VIGILÂNCIA EPIDEMIOLÓGICA}

Suspeita-se de hantavirose quando se observa quadro febril seguido por síndrome do desconforto respiratório agudo (SDRA), sem que haja fatores predisponentes que a expliquem. Também são suspeitos os quadros febris em que há evolução radiológica com infiltrado bilateral e com necessidade de suplementação de oxigênio. Deve-se pesquisar a SPCVH quando se observa à necropsia a presença de edema pulmonar não cardiogênico ou quando não haja causa mortis específica identificável. $(3,18,27,43,61)$

Em áreas onde se confirmam casos de SPCVH, pode-se ampliar a vigilância incluindo também o rastreamento de casos febris com discreto acometimento pulmonar ou com presença de doença renal e outras síndromes febris. ${ }^{(61)}$

Devem ser tomados cuidados no transporte de amostras para pesquisa laboratorial, utilizando-se embalagens inquebráveis, para evitar exposições inadvertidas. Também é importante, durante 0 transporte, a identificação do conteúdo como material biológico contaminado.(43)

Pesquisas epidemiológicas e sorológicas dos roedores aprisionados têm sido realizadas com o intuito de determinar-se qual ou quais espécies virais são responsáveis pela SPCVH e qual ou quais os seus roedores hospedei$\operatorname{ros}^{(27,28,43,61)}$ 


\section{NOTIFICAÇÕES}

No B rasil, os casos suspeitos de SPCVH devem ser notificados à Vigilância Epidemiológica do município de ocorrência. Os relatos epidemiológicos periódicos são fornecidos pela Fundação Nacional de Saúde (Funasa). Os laboratórios de virologia licenciados para o diagnóstico de hantavirose são o do Instituto Adolfo Lutz, em São Paulo, SP (tel. 11 3068-2904) e o do Instituto Evandro Chagas, em Belém, PA. Entretanto, à medida que aumentam os casos notificados e se descobre ser freqüente a infecção por hantavírus, em nosso país seria interessante que um número maior de laboratórios atuasse promovendo esse diagnóstico.

Nos EUA, O CDC (Centers for Disease Control and Prevention - www.cdc.gov./ ncidod/ diseases/ hanta/ hps/ index/ htm) elabora periodicamente os dados epidemiológicos acerca da SPCVH.

\section{Perspectivas}

Recentemente Hooper et al. desenvolveram um modelo animal de SPCVH, causando infecção e doença letal por vírus Andes num tipo de hamster, conhecido como hamster sírio. As características da doença nos hamsters, incluindo período de incubação, desenvolvimento rápido e progressivo de insuficiência respiratória, e os achados patológicos de edema pulmonar e derrame pleural, são muito semelhantes à SPCVH em humanos. ${ }^{(78)} \mathrm{O}$ modelo animal cria perspectivas para o melhor conhecimento da fisiop atologia e imunomodulação da doença e, assim, para o controle do edema pulmonar e do choque a ela associados. Também o desenvolvimento de vacinas ficará facilitado em estudos com modelo animal. ${ }^{(78,79)}$

Tendo em vista o mecanismo de patogênese viral, outra importante vertente de estudos é a determinação da proteína de ligação viral e o desenvolvimento de anticorpos que a reconheçam e bloqueiem sua interação com as integrinas. ${ }^{(79)}$

Como na patogênese da doença predominam os mecanismos imunológicos, a administração de anticorpos neutralizantes, obtidos de soro de pacientes convalescentes, ou de anticorpos monoclonais podem ser medidas promissoras e encontram-se em avaliação. ${ }^{(18,80)}$

\section{CONCLUSÃo}

Por sua recente descrição, a SPCVH ainda é objeto de investigação, o que, somado à sua extensa distribuição geográfica e sua crescente incidência fazem-nos supor que esta doença é ainda pouco reconhecida e diagnosticada em nosso meio. $31-34,42,48)$

Ressaltamos que os vírus J uquitiba, Araraquara e Castelo dos Sonhos estão associados à SPCVH no B rasil. Trata- se de uma doença nova que precisa ser melhor estudada, levando em conta a ampliação da vigilância para formas mais leves da doença, formas febris com acometimento renal e doença na faixa etária pediátrica. Também não se pode garantir que não haja transmissão interpessoal, sendo importante a adoção de medidas de isolamento geral e respiratório em casos suspeitos. ${ }^{(18,27,43,61)}$

É importante salientar que, por seus pródromos inespecíficos e curso clínico fulminante, faz-se necessário que se esteja alerta para a ocorrência da SPCVH, especialmente entre os pneumologistas e intensivistas, pois o encaminhamento para centros de referência terciários e a adoção de suporte intensivo adequado são medidas de grande impacto na sobrevida desses pacientes.

\section{AgRAdECIMENTOS}

A Carlos André Santos Pincelli, pela revisão do manuscrito, e ao Dr. Rodrigo F. Reiff, pela ajuda com o material fotográfico.

\section{REFERÊNCIAS}

1. Centers for Disease Control and Prevention. Outbreak of acute illness - southwestern United States. MMWR Morb Mortal Wkly Rep 1993; 42:421-4

2. Centers for Disease Control and Prevention. Update: Hantavirus disease - United States, 1993. MMWR Morb Mortal Wkly Rep 1993;42: 612-4.

3. Centers for Disease Control and Prevention. Update: Hantavirus pulmonary syndrome - United States. MMWR Morb Mortal Wkly Rep 1999;48:521-5.

4. Nichol ST, Spiropoulou CF, Morzunov S, Rollin PE, Ksiazek TG, Feldmann $\mathrm{H}$, et al. Genetic identification of a hantavirus associated with an outbreak of acute respiratory illness. Science 1993;262:914-7.

5. Cameron S. Hantavirus cardiopulmonary syndrome. Med J 2001;2:121 (cited 2001 J un 8). A vailable from: http:/ / www.emedicine.com/ emerg/ topic861.htm.

6. Hughes MJ, Peters CJ, Cohen ML, Mahy BW. Hantavirus pulmonary syndrome: an emerging infectious disease. Science 1993;262:850-1.

7. Hjelle B. Hantavirus with emphasis on four corners hantavirus. University of New Mexico School of Medicine 1995 (on-line). (cited 1999 Oct 3). A vailable from: http:/ / web.uct.ac.za/ depts/ microbiology/ cann/ 335/ $\mathrm{H}$ antaviruses/ html.

8. Hallin GW, Simpson SQ, Crowell RE, J ames DS, Koster FT, Mertz GJ , et al. Cardiopulmonary manifestations of hantavirus pulmonary syndrome. Crit Care Med 1996;24:252-8.

9. Duchin J, Koster F, Peters CJ , Simpson G, Tempest B, Zaki S, et al. Hantavirus Study Group: Hantavirus pulmonary syndrome: a clinical description of 17 patients with a newly recognized disease. N Engl J Med 1994;330:949-55.

10. Simonsen L, Dalton MJ, Breiman RF, Hennessy T, U mland ET, Sewell CM, et al. Evaluation of the magnitude of the 1993 hantavirus outbreak in the southwestern United States. J Infect Dis 1995;172:72933.

11. Mills J N, Ksiasek TG, Ellis BA, Rollin PE, Nichol ST, Yates TL, et al. Patterns of association with wild hosts and habitat: antibody reactive with sin nombre virus in small mammals in the major biotic communities of the southwestern United States. Am J Trop Med Hyg 1997;56: 273-84. 
12. Childs J E, Ksiazek TG, Spiropoulou CF, Krebs J W, Morzumov S, Maupin $\mathrm{GO}$, et al. Serologic and genetic identification of Peromyscus maniculatus as the primary rodent reservoir for a new hantavirus in the southwestern U nited States. J Infect Dis 1994;169:1271-80.

13. Lee $H$, Lee $P$, J ohnson $K$. Isolation of an etiologic agent of Korean fever. J Infect Dis 1978;137:298-308.

14. Peters CJ, Simpson GL, Levy H. Spectrum of hantavirus infection: hemorrhagic fever with renal syndrome and hantavirus pulmonary syndrome. Annu Rev Med 1999;50:531-45.

15. Peters CJ . Bunyaviridae-California encephalitis, hantavirus pulmonary syndrome and Bunyavirid hemorrhagic fevers. In: Mandell: principles and practice of infectious diseases. $5^{\text {th }}$ ed. New York: Churchill Livingstone, 2000.

16. Butler $\int$, Peters $\mathrm{C}$ J . H antaviruses and hantavirus pulmonary syndrome. Clin Infect Dis 1994;19:387-94.

17. Peters CJ , Khan AS. Hantavirus pulmonary syndrome: the new American hemorrhages fever. Clin Infect Dis 2002;34:1224-31.

18. Centers for Disease Control and Prevention. All about hantavirus. $\mathrm{H}$ antavirus pulmonary syndrome. (cited $2003 \mathrm{~J}$ an 18). A vailable from: http:/ / www.cdc.gov/ ncidod/ disease/ hanta/ hps/ index.htm.

19. Van Bevern PA. Hantavirus pulmonary syndrome: how great a threat? Clin Rev 2000;10:108-18.

20. Sosa-Estani S, Salomon OD, Gomez AO, Esquivel ML, Segura EL. Regional differences and hantavirus pulmonary syndrome. Cad Saude Publica 2001;17(Suppl):47-57.

21. Baró AM, Vergara J O, Navarrete MC. H antavirus en Chile: revisión y análisis de casos desde 1975. Rev Med Chil 1999;127:1513-23.

22. Sotomayor VEUP, A guilera XS. Epidemiologia de la infeccion humana por hantavirus en Chile. Rev Chil Infect 2000;17:220-32.

23. Padula PJ, Colavecchia SB, Martínez VP, Gonzalez Della Valle MO, Edelstein A, Miguel SD, et al. Genetic diversity, distribution, and serological features of hantavirus infection in five countries in South America. J Clin Microbiol 2000;38:3029-35.

24. Zhao X, Hay J. The evolution of hantavirus. Immunol Invest 1997; 26:191-7.

25. J ohnson AM, Souza LTM, Ferreira IB, Pereira LE, Ksiazek TG, Rollin $P E$, et al. Genetic investigation of novel hantaviruses causing fatal HPS in Brazil. J Med Virol 1999;59:527-35.

26. Enria DA, Pinheiro F. Rodent-borne emerging viral zoonosis. Infect Dis North Am 2000;14:167-84.

27. Organizacion Panamericana de la Salud. Cuaderno tecnico 47 . Hantavirus en las Americas: guia para el diagnóstico, el tratamiento, la prevención y el control. Rev Esp Salud Publica 1999;73:647-70.

28. Pereira LE, Souza LTM, Souza RP, Bisordi I, Susuki A, Katz G. H istórico da vigilância eco-epidemiológica do hantavírus no Brasil. Governo do Estado de São Paulo. Secretaria de Estado da Saúde. Rev Coord Inst Pesq 1999;1:5-12.

29. Childs J E, Krebs J W, Ksiazek TG, Maupen GO, Gage KL, Rollin PE, et al. A house hold-based, case-control study of environmental factors associated with hantavirus pulmonary syndrome in the south-western United States. Am J Trop Med 1995;52:393-7.

30. Engelthaler DH, Mosley DG, Cheek J E, Levy CE, Komatsu KK, Ettestad $P$, et al. Climatic and environmental patterns associated with hantavirus pulmonary syndrome, Four Corners region, U nited States. Emerg Infect Dis 1999;5:87-94.

31. Romano-Lieber NS, Yee J, H jelle B. Serologic survey for hantavirus infections among wild animals in rural areas of Sao Paulo State, B razil. Rev Inst Med Trop Sao Paulo 2001;43:325-7.

32. Campos GM. Estudo clínico-epidemiológico sobre a hantavirose na região de Ribeirão Preto, SP [dissertação]. São Paulo: Faculdade de Medicina de Ribeirão Preto, Universidade de São Paulo, 2002.

33. Figueiredo LTM, Campos GM, Rodrigues B. Síndrome pulmonar e cardiovascular por hantavírus: aspectos epidemiológicos, clínicos, do diagnóstico laboratorial e do tratamento. Rev Soc Bras Med Trop 2001; 34:13-23.

34. Figueiredo LTM, Forster AC, Fulhorst C, Rodrigues EMS, Koster F, Campos GM, et al. Contribuição ao diagnóstico, ao tratamento, à epidemiologia e ao controle da síndrome pulmonar e cardiovascular por hantavírus. Informe Epidemiol SUS 2000,9:167-78.

35. Enria D, Padula $P$, Segura EL, Peni N, Edelstein A, Posse $C R$, et al. Hantavirus pulmonary syndrome in Argentina. Possibility of personto-person transmission. Medicina (B Aires) 1996;56:709-11.

36. Wells RM, Sosa Estani S, Yadon ZE, Enria D, Padula P, Pini N, et al. An unusual hantavirus outbreak in Southern Argentina: person-to-person transmission? Emerg Infect Dis 1997,3:171-4.

37. Silva MV, Vasconcelos MJ, Hidalgo NTR, Veiga APR, Canzian M, Marotto PCF, et al. Hantavirus pulmonary syndrome. Report of the first three cases in São Paulo, Brazil. Rev Inst Med Trop Sao Paulo 1997;39:231-4

38. BRASIL-COVEV/CGVEP/CENEPI/ FUNASA/MS. H antavirose: casos e óbitos confirmados por laboratório por Estado e total Brasil, 19932002 (dados preliminares até 30 de outubro de 2002).

39. Brasil. Secretaria de Estado da Saúde do Paraná. (citado 2003 mar 22). Disponível em: http:/ / www.saude.pr.gov.br/ agravos/ hantavírus/ aspectos_epidemiologicos.htm.

40. Smaljohn C, Hjelle B. Hantavirus: a global disease problem. Emerg Infect Dis 1997;3:95-104.

41. Figueiredo LTM, Moreli ML, A Imeida VSO, Felix PR, Bruno J C, Ferreira IB, et al. H antavirus pulmonary syndrome (HPS) in Guariba, SP, Brazil. Report of 2 cases. Rev Inst Med Trop Sao Paulo 1999;41:131-7.

42. Iversson LB, Travassos da Rosa APA, Rosa MDB, Lomar AV, Sasaki MGM , LeDuc J W. Infecção humana por hantavírus no sul e sudeste do Brasil. Rev Assoc Med Bras 1994;40:85-92.

43. Centers for Disease Control and Prevention. Hantavirus pulmonary syndrome - United States: updated recommendation for risk reduction. MMWR Morb Mortal Wkly Rep 2002;51:1-12.

44. Morelli M, Figueiredo LTM. Detection of the genome of B razilian hantavirus in human blood samples by nested-RT-PCR. J Virol Methods 2002.

45. Holmes RR, Boccanera R, Figueiredo LTM, Mançano SR, Pane C. Seroprevalence of human hantavirus infection in the Ribeirão Preto region of São Paulo State, B razil. Emerg Infect Dis 2000;6:5-6.

46. Campos GM, Sousa RLM, Badra SJ, Pane C, Figueiredo LTM. Hantavirus serologic survey in J ardinópolis County, SP, Brazil. J Med Virol 2003. [Submetido]

47. Silva-Vergara ML, Costa J J J C, Barata CH, Curi VGM, Tiveron J r CG, Teixeira AC. Hantavirus pulmonary syndrome in U beraba, Minas Gerais, Brazil. Mem Inst O swaldo Cruz 2002; 97:783-7.

48. Mendes WS, Aragão NJ L, Santos HJ, Raposo L, Vasconcelos PFC, Rosa EST, et al. Hantavirus pulmonary syndrome in A najatuba, Maranhão, Brazil. Rev. Inst Med Trop Sao Paulo 2001;43:237-40.

49. Young J C, H ansen GR, Graves TK, Deasy MP, Humphreys J G, Fritz $C L$, et al. The incubation period of hantavirus pulmonary syndrome. Am J Trop Med Hyg 2000;62:714-7.

50. Zaki SR, Greer PW, Coffield LM, Goldsmith CS, Nolte KB, Foucar K, et al. Hantavirus pulmonary syndrome: pathogenesis of an emerging infectious disease. Am J Pathol 1995;146:552-79.

51. Khan AS, Khabbaz RF, Armstrong LR, Holman RC, Bauer SP, Graber J, et al. Hantavirus pulmonary syndrome: the first 100 US cases. J Infect Dis 1996;173:1297-303.

52. Bharadwaj M, Nofchissey R, Goade D, Koster F, H jelle B. Humoral immune response in hantavirus cardiopulmonary syndrome. J Infect Dis $2000 ; 182: 43-8$.

53. Terajima M, H endershot J D 3rd, Kariwa H, Koster FT, H jelle B, Goade $D$, et al. $H$ igh levels of viremia in patients with hantavirus pulmonary syndrome. J Infect Dis 1999;180:2030-4. 
54. Mori M, Rothman AL, Kurane I, Montoya J M, Nolte KB, Norman J E et al. High levels of cytokine-producing cells in the lung tissues of patients with fatal hantavirus pulmonary syndrome. J Infect Dis 1999: 179:295-302.

55. Crowley MR, Katz RW, Kessler R, Simpson SQ, Levy H, H allin GW, et al. Successful treatment of adults with severe hantavirus pulmonary syndrome with extracorporeal membrane oxygenation. Crit Care Med 1998;26:409-14.

56. Goade DE, Nofchissey RA, Lanzi R, et al. Long-term fatigue, proteinuria and pulmonary sequelae following H PS. In: Fifth International Conference on Hemorrhagic Fever with Renal Syndrome (HFRS), Hantavirus Pulmonary Syndrome (HPS), and Hantaviruses (Mérieux Foundation), 2001. A bstract book. p.1:21.

57. Passaro DJ, Shieh WJ, H acker J K, Fritz CL, Hogan SR, Fischer $M$, et al. Predominant kidney involvement in a fatal case of hantavirus pulmonary syndrome caused by Sin Nombre virus. Clin Infect Dis 2001; 33:263-4.

58. Zavasky DM, Hjelle B, Peterson MC, Denton RW, Reimer L. Acute infection with Sin Nombre hantavirus without pulmonary edema. Clin Infect Dis 1999;29:664-6.

59. Boroja M, Barrie J R, Raymond GS. Radiographic findings in $20 \mathrm{pa}-$ tients with hantavirus pulmonary syndrome correlated with clinical outcome. AJ R Am J Roentgenol 2002;178:159-63.

60. Ketai LH, Williamson MR, Telepak RJ, Levy H, Koster FT, Nolte KB, et al. $\mathrm{H}$ antavirus pulmonary syndrome: radiographic findings in 16 patients. Radiology 1994;191:665-8.

61. Centers for Disease Control and Prevention. Case definitions for infectious conditions under public heath surveillance. MMWR Morb Mortal Wkly Rep 1997;46:1-55.

62. Smith RC, Mann H, Greenspan RH, Pope CF, Sostman HD. Radiographic differentiation between different etiologies of pulmonary edema. Invest Radiol 1987;22:859-63.

63. Morgan PW, Goodman LR. Pulmonary edema and adult respiratory distress syndrome. Radiol Clin North Am 1991;29:943-63.

64. Pistolese M, Miniati M, Milne EN, Giuntini $C$. The chest roentgenogram in pulmonary edema. Clin Chest Med 1985;11:593-619.

65. Feldmann H, Sanchez A, Morzunov S, Spiropoulou CF, Rollin PE, Ksiazek TG, et al. Utilization of autopsy RNA for the synthesis of the nucleocapsid antigen of a newly recognized virus associated with hantavirus pulmonary syndrome. Virus Res 1993;30:351-67.

66. Padula PJ, Rossi CM, Della Valle MO, Martínez PV, Colavecchia SB, Edelstein $A$, et al. Development and evaluation of a solid-phase enzyme immunoassay based on Andes hantavirus recombinant nucleoprotein. J Med Microbiol 2000;49:149-55.
67. Mertz GJ . Bunyaviridae: bunyaviruses, phleboviruses, nairoviruses, and hantaviruses. In: Richmann DD, Whitley RJ , Hayden FG, editors. Clinical virology. New York: Churchill Livingstone, 1997;943-72.

68. LeDuc J W, Smith GA, Pinheiro FP, Vasconcelos PF, Rosa ES, Maiztegui JI. Isolation of a $\mathrm{H}$ antaan-related virus from Brazilian rats and serologic evidence of its widespread distribution in South A merica. Am J Trop Med Hyg 1985;34:810-5.

69. Koster F, Foucar K, H jelle B, Scott A, Chong Y-Y, Larson, McC abe M. Rapid presumptive diagnosis of hantavirus cardiopulmonary syndrome by peripheral blood smear. Am J Clin Pathol 2001;116:665-72.

70. Nolte KB, Feddersen RM, Foucar K, Zaki SR, Koster FT, Madar D, et al. Hantavirus pulmonary syndrome in the U nited States: a pathological description of a disease caused by a new agent. Hum Pathol 1995; 26:110-20.

71. Colby TV, Zaki SR, Feddersen RM, Nolte KB. Hantavirus pulmonary syndrome is distinguishable from acute interstitial pneumonia. Arch Pathol Lab Med 2000;124:1463-6.

72. Mackow ER, Gravilovskaya IN. Cellular receptors and hantavirus pathogenesis. Curr Top Microbiol Immunol 2001;256:91-115.

73. Peters CJ, Zaki SR. Role of endothelium in viral hemorrhagic fevers. Crit Care Med 2002;30:S268-73.

74. A mato MBP, Barbas CSV, Medeiros DM, Magaldi RB, Schettino GPP, Lorenzi $\mathrm{G}$, et al. Effect of a protective-ventilation strategy on mortality in the acute respiratory distress syndrome. N Engl J Med 1998;338: 347-54.

75. Bernard GR, Artigas A, B ringham KI, Carlet J, Falke K, Hudson L, et al. The American-European Consensus Conference on ARDS - Definitions, mechanisms, relevant outcomes and clinical trial coordination. Am J Respir Crit Care Med 1994;149:818-24.

76. Chapman LE, Mertz GJ, Peters CI, J olson HM, Khan AS, Ksiazek TG, et al. Ribavirin Study Group. Intravenous ribavirin for hantavirus pulmonary syndrome: safety and tolerance during 1 year of open-label experience. Antivir Ther 1999;4:211-9

77. Chapman LE, Ellis BA, Koster FT, Sotir M, Ksiazek TG, Mertz GJ , et al. Ribavirin Study Group. Discriminators between hantavirus infected and uninfected persons enrolled in a trial of intravenous ribavirin for presuntive hantavirus pulmonary syndrome. Clin Infect Dis 2002;34: 293-304.

78. Hooper J W, Larsen T, Custer DM, Schmaljohn CS. A lethal model for hantavirus pulmonary syndrome. Virology 2001;289:6-14.

79. Enserink M. Finally a handle on the hantaviruses. Science $2001 ; 293$ : 1414-15.

80. Graziano KL, Tempest B. Hantavirus pulmonay syndrome: a Zebra worth knowing. Am Fam Physician 2002;66:1015-20. 